\title{
LOS ENCLAVES PROVINCIALES EL CASO DEL CONDADO DE TREVIÑO
}

\author{
JOSÉ JUAN SERVER GALLEGO
}

\author{
SUMARIO \\ I. CONSIDERACIONES PREVIAS. \\ II. CLASIFICACION DE LOS ENCLAVES PROVINCIALES. \\ III. LA PROBLEMATICA DE LOS ENCLAVES. \\ IV. LAS VIAS LEGALES DE DESAPARICION DE ENCLAVES. \\ V. EL CASO DEL CONDADO DE TREVIÑO.
}

\section{CONSIDERACIONES PREVIAS.}

El presente trabajo gira en torno a una realidad poco conocida y que suele pasar totalmente desapercibida: los enclaves provinciales. El enclave provincial es la porción del territorio de una provincia separada de la misma y totalmente rodeada por el territorio de otra u otras provincias. El único enclave algo más conocido por el público en general es el Condado de Treviño, sin duda debido a la extensión de su territorio y al hecho de que, a diferencia de los demás, suele figurar en todos los mapas que incluyen la división provincial. Sin embargo, los enclaves son una realidad bastante extendida y, como luego veremos, pueden conllevar en ocasiones cierta problemática, circunstancia que aconseja prestarles alguna atención. El caso concreto del Condado de Treviño ha llegado incluso a ser objeto de una sentencia del Tribunal Constitucional (1), cuyo análisis es el origen y el objeto principal de este breve estudio.

Los enclaves son particularmente abundantes en la zona centro de la mitad septentrional de España y, concretamente, entre las Comunidades de Castilla-León, País Vasco y Cantabria, siendo muy escasos en la mitad meridional. Su origen, en opinión de Gómez Fernández (2), se sitúa en la época de la Reconquista y su evolución histórica corre paralela a las vicisitudes de la división territorial de nuestro país. De ahí que, seguidamente, hagamos un breve repaso de la historia de dicha división territorial, siguiendo en este punto a Martín-Retortillo (3).

Considera el citado autor que a lo largo del Antiguo Régimen no pudo alcanzarse una ordenación territorial única y con validez general y que el sistema de Intendencias del siglo XVIII no canceló globalmente la heterogénea multiplicidad de circunscripciones territoriales existentes en España. El primer intento de modificación global del mapa político-administrativo de Carlos III fue la división prefectoral establecida por José I mediante Decreto de 17 de abril de 1810, división que no se inspiraba en criterios históricos y que, por tanto, no contemplaba la existencia de enclaves. Por otra parte, en ejecución de lo dispuesto por la Constitución de Cádiz, el Decreto LIX de 22 de enero de 1822 de las Cortes extraordinarias, sancionó una 
división provincial, de carácter igualmente ahistórico, que suprimió radicalmente los enclaves. Pero el fin del Trienio Liberal supuso el retorno a las divisiones anteriores.

Posteriormente, por Decreto de 30 de noviembre de 1833, Javier de Burgos estableció la división provincial que ha perdurado hasta nuestros días. MartínRetortillo, siguiendo la opinión de Guaita, considera que este Decreto sí respetó al máximo las divisiones históricas, asumiendo en ocasiones límites que ya entonces tenían más de dos siglos de vigencia. La división provincial de Javier de Burgos sí respetó los tradicionales enclaves, que han perdurado así hasta nuestros días, incorporándose con sus respectivas provincias al actual mapa autonómico.

Conviene aclarar que los enclaves provinciales no constituyen el único tipo de enclave territorial existente. También existen enclaves municipales, entendiendo por enclave municipal la porción de un término municipal separada del mismo y totalmente rodeada por otro u otros términos municipales (4). Pero, como señala Larumbe Biurrun (5), dada su escasa problemática y su excepcionalidad, no requieren que se les preste mayor atención.

También existe un caso de lo que podríamos denominar "enclave internacional". Se trata de Llivia, municipio de la provincia de Gerona, situado al NE. de Puigcerdá, en la Cerdaña y enclavado en territorio francés, a dos Kilómetros de la frontera con España. Su origen data del tratado de los Pirineos de 7 de noviembre de 1659. Obviamente, este caso es sustancialmente distinto de los anteriores, habida cuenta de que aquí ya no se trata de una simple cuestión de límites provinciales, sino que entran en juego cuestiones tales como las fronteras internacionales y el ámbito de soberanía de los Estados, además de que su problemática también es distinta.

\section{CLASIFICACION DE LOS ENCLAVES PROVINCIALES.}

Como ya hemos dicho al principio, podemos entender por enclave provincial la porción del territorio de una provincia separada de la misma y totalmente rodeada por el territorio de otra u otras provincias.

A efectos meramente expositivos, y dada su distinta problemática, conviene distinguir dos tipos básicos de enclaves provinciales.

1.- Enclaves comunitarios: se trata del caso en que el enclave se encuentra separado del territorio de la Comunidad Autónoma a la que pertenece y totalmente rodeado por el territorio de otra u otras Comunidades Autónomas. Se subdividen en:

A) Intercomunitarios: rodeados por el territorio de más de una Comunidad Autónoma. Es el caso del Rincón de Ademuz, perteneciente a la provincia de Valencia y, por ende, a la Comunidad Valenciana, y situado entre las Comunidades de Castilla-La Mancha y Aragón (6). La causa de este singular enclave se remonta a la Reconquista, durante la cual Jaime I respetó los tratados con Castilla y Aragón por los cuales se consideraba a Santa Cruz de Moya, municipio castellano que separa al Rincón de Ademuz del territorio Valenciano, de gran importancia estratégica y geográfica, por ser camino obligatorio entre Aragón y Castilla. Ello determinó para el futuro el que el Rincón no esté unido al resto de su Comunidad (7). 
B) Enclaves intracomunitarios: rodeados por el territorio de una sóla Comunidad Autónoma. Es el caso de Villaverde de Trucios, perteneciente a Cantabria y encavado en Vizcaya; el Condado de Treviño, perteneciente a Burgos y enclavado en Alava; Petilla de Aragón, perteneciente a Navarra y enclavado en Zaragoza; Cezura y Lastrilla, pertenecientes a Palencia y enclavadas en Cantabria; Sajuela y Ternero, pertenecientes a Burgos y enclavados en La Rioja.

2.- Enclaves no comunitarios o provinciales en sentido estricto: se trata de aquellos enclaves que, aún estando separados de la provincia a la que pertenecen, no lo están totalmente de su Comunidad Autónoma. Se subdividen en:

A) Interprovinciales: rodeados por el territorio de más de una provincia. Es el caso de Berzosilla, perteneciente a Palencia y enclavada entre Cantabria y Burgos; Orduña, perteneciente a Vizcaya y enclavada entre Alava y Burgos; Quintanilla del Molar y Roales, pertenecientes a Valladolid y enclavados entre León y Zamora; Anchuras, perteneciente a Ciudad Real y enclavada entre Toledo y Badajoz.

B) Intraprovinciales: totalmente rodeados por el territorio de una sóla provincia. Es el caso de Villodrigo, perteneciente a Palencia y enclavado en Burgos.

\section{LA PROBLEMATICA DE LOS ENCLAVES.}

El único fundamento que puede tener hoy en día el mantenimiento de los enclaves es el respeto a la tradición histórica, que en algún caso podrá, además, estar acompañada de la voluntad favorable de los habitantes de dichos enclaves a mantener su statu quo. Por otro lado, dicho mantenimiento no deja de plantear dificultades. En efecto, al margen de las comprensibles "aspiraciones anexionistas" que puedan surgir en las provincias o Comunidades Autónomas en las que estén enclavados estos territorios, no puede ignorarse la existencia de otros problemas que sí son dignos de tener en consideración. Estos problemas son, básicamente, y dejando a un lado los casos puntuales, de dos órdenes:

1.- En primer lugar, la dependencia administrativa del enclave de una provincia de la que se encuentra totalmente separado supone ir en contra del principio de máxima proximidad de la Administración al administrado y puede ocasionar a sus habitantes la necesidad de desplazarse, para realizar determinados trámites, a poblaciones muy distantes de su lugar de residencia y distintas de aquéllas a las que, de hecho, se encuentran geográficamente vinculados y donde realizan la mayor parte de los actos de la vida diaria, tales como su actividad profesional, compras u ocio. Ello puede ocasionar el deseo, por parte de dichos habitantes, de pasar a depender de la provincia en la que están enclavados. Esto es lo que ha sucedido, por ejemplo, en el Condado de Treviño.

2.- En el caso de los enclaves intracomunitarios -es decir, aquellos que, estando separados de la Comunidad Autónoma a la que pertenecen, están rodeados por el territorio de una sóla Comunidad Autónoma- puede darse un segundo orden de problemas; se trata, concretamente, del caso en que una Comunidad pretenda llevar a cabo determinadas actuaciones en un área en el que se encuentre comprendido un enclave de otra Comunidad. Los ejemplos son múltiples, pero baste citar aquí algunos de ellos: construcción de carreteras o ferrocarriles cuyo itinerario se desarrolle 
íntegramente en el territorio de la Comunidad, ordenación del transporte desarrollado por estos medios o por cable, construcción de canales y regadíos, ordenación del turismo, vías pecuarias, ordenación del territorio y urbanismo. Particular interés tienen, a este respecto, las medidas de protección del medio ambiente, cuya eficacia requiere frecuentemente actuaciones homogéneas en áreas extensas.

En todos estos casos, la actuación prevista puede verse seriamente dificultada, cuando no imposibilitada, por la presencia de una porción aislada de territorio en la que la Comunidad no puede actuar, planteándose en todo caso la necesidad de llegar a acuerdos con otra Comunidad o, en su caso, con el Estado.

Ciertamente, este segundo orden de problemas no será frecuente en la práctica, habida cuenta del reducido tamaño que tienen la mayoría de los enclaves y del hecho de que suelen estar muy próximos al límite de la Comunidad a la que pertenecen. Pero, aunque sea de forma esporádica, pueden darse en algún caso. Prueba de ello es el conflicto positivo de competencias 616/87 promovido por el Consejo de Gobiemo de la Diputación Regional de Cantabria frente al Gobierno Vasco en relación con diferentes actuaciones que se imputan a éste último dentro del territorio de Villaverde de Trucios.

\section{LAS VIAS LEGALES DE DESAPARICION DE ENCLAVES.}

Analizada la problemática que conlleva el mantenimiento de los enclaves, parece oportuno estudiar ahora las posibles vías de supresión de los mismos.

La desaparición de los enclaves, con la nueva adscripción provincial de los respectivos territorios, plantea problemas diferentes según las circunstancias del caso concreto. Para empezar, está el problema de determinar la provincia a la cual incorporar el enclave en el caso de que éste sea interprovincial; en tal caso, un posible criterio a seguir es el de la voluntad de los habitantes del enclave.

En cuanto a los aspectos estrictamente jurídicos del proceso, analizaremos por separado el supuesto de los enclaves comunitarios y el de los no comunitarios o provinciales en sentido estricto. Previamente hay que señalar que, con carácter general, el artículo 141.1 de la Constitución establece que "cualquier alteración de los límites provinciales habrá de ser aprobada por las Cortes Generales mediante ley orgánica".

1.- En el caso de los enclaves no comunitarios o provinciales en sentido estricto, su desaparición como tales enclaves se regirá por las normas que regulan el cambio de límites provinciales; concretamente por el artículo 25.2 del Real Decreto Legislativo 781/1986 (8) que, según su Disposición Final séptima, letra a), tiene carácter de legislación básica. Este precepto se limita a repetir que cualquier alteración de los límites provinciales exigirá ley orgánica, sin establecer expresamente ningún otro trámite. Lo normal, en el caso que nos ocupa, será que el proceso se ponga en marcha por acuerdo adoptado por el Ayuntamiento o Ayuntamientos del enclave en cuestión. En cualquier caso será conveniente convocar un referéndum entre los habitantes del mismo para que éstos puedan manifestar democráticamente su parecer respecto al cambio de adscripción provincial.

En cuanto a la regulación de dicho referéndum, es necesario distinguir el supuesto de que sea celebrado por el propio Ayuntamiento o Ayuntamientos interesados, del supuesto de que sea celebrado por el Estado. 
En el primer caso, no será aplicable la Ley Orgánica Reguladora de las Distintas Modalidades de Referéndum (9), ya que su Disposición Adicional establece que las normas de dicha ley "...no alcanzan en su regulación a las consultas populares que puedan celebrarse por los Ayuntamientos, relativas a asuntos relevantes de índole municipal, en sus respectivos territorios, de acuerdo con la legislación del Régimen Local, y a salvo, en todo caso, la competencia exclusiva del Estado para su autorización". Sí será, en cambio, aplicable el artículo 71 de la Ley Reguladora de las Bases del Régimen Local, de modo que será necesario el previo acuerdo del Pleno municipal por mayoría absoluta y la autorización del Gobierno de la Nación, además del cumplimiento de los demás requisitos que, en su caso, establezca la legislación de las Comunidades Autónomas con competencias en la materia.

En el caso de que la consulta popular sea celebrada por el Estado, habrá que entender aplicables las normas de la ya mencionada Ley Orgánica Reguladora de las Distintas Modalidades de Referéndum. En este caso no jugará, obviamente, lo dispuesto en el artículo 71 de la Ley Reguladora de las Bases del Régimen Local.

2.- En el caso de los enclaves comunitarios, la desaparición del enclave conlleva una alteración en el ámbito territorial de dos Comunidades Autónomas. Ello nos obliga a prestar atención al régimen que regula dichas alteraciones y, por consiguiente, a lo que establezcan los respectivos Estatutos de Autonomía.

El artículo 147.2.b de la Constitución prescribe, como contenido necesario de los Estatutos de las Comunidades Autónomas, la "delimitación de su territorio". Ello ha dado lugar a normas estatutarias de contenido diverso. Como aclara el Tribunal Constitucional, en la ya mencionada Sentencia 99/86, fundamentos 4 y 5 , "en unos casos, el territorio de la Comunidad Autónoma es definido por relación al de los municipios integrados en la provincia o provincias que contribuyen a crear el nuevo Ente autónomo y acceden así a su autogobierno. ...Puede así decirse que en este modo de delimitar el territorio autonómico se actúa mediante normas cuyo objeto no es, en rigor, el territorio mismo, sino el ámbito espacial de aplicación de los actos y disposiciones jurídicas pertenecientes al subsistema normativo de cada Comunidad Autónoma". En estos casos, tanto la inclusión como la exclusión de municipios en las provincias que integran la Comunidad Autónoma y, por tanto, la incorporación o segregación de enclaves, no supondrán reforma del Estatuto de Autonomía y se regirán por lo ya expuesto para el caso de que no haya cambio de Comunidad Autónoma. En sentido contrario se pronuncia Rivero Ysern (10), pues considera necesario acudir, en todo caso, al procedimiento de reforma estatutaria.

Como sigue diciendo el Tribunal, "En otros casos, lo normado no es ya tan sólo el ámbito de aplicabilidad de las disposiciones autonómicas y de los actos de sus órganos, sino el territorio mismo como espacio natural. Se introduce así en el Estatuto una específica garantía territorial mediante la cual los límites geográficos con los que se constituyó al nacer la Comunidad Autónoma quedan consagrados en su norma institucional básica. Así, el Estatuto de Autonomía del País Vasco, con expresión análoga a las que se encuentra en otros Estatutos, se refiere, en su artículo 2.2, a los 'actuales límites' de los Territorios Históricos que integran esta 
Comunidad. Esta segunda forma de delimitación del territorio impide toda alteración del mismo que no se realice mediante el procedimiento establecido para la revisión del Estatuto...". Así pues, si una o ambas Comunidades Autónomas se encuentran en este segundo caso, además de los trámites anteriormente expuestos para la alteración de los límites provinciales, habrá que proceder a la reforma del Estatuto o Estatutos correspondientes. En este caso, la ley orgánica de reforma del Estatuto puede servir, al mismo tiempo, para satisfacer la exigencia del artículo 141.1 de la Constitución, opinión también sostenida por Luis María Diez-Picazo (11).

Ahora bien; puede ocurrir que los Estatutos de Autonomía establezcan procedimientos especiales de segregación o agregación de enclaves. En tal caso habrá que estar, obviamente, a lo establecido en dichos Estatutos. Sólo los Estatutos del País Vasco y Aragón (12) establecen procedimientos de incorporación de enclaves a su territorio y sólo el de Castilla-León establece un procedimiento de segregación.

\section{EL CASO DEL CONDADO DE TREVIÑO.}

El Condado de Treviño es un enclave intracomunitario situado al sur de la provincia de Alava y perteneciente a la de Burgos. Está integrado por los municipios de La Puebla de Arganzón y Treviño. Su extensión es mucho mayor que la normal de los enclaves y sólo pueden compararse a ella la del Rincón de Ademuz (Valencia) y la de Anchuras (Ciudad Real).

En cuanto al origen histórico de este enclave, el Condado de Treviño, región conocida en el medioevo como Ibida, lleva vida independiente de Alava desde hace, al menos, ocho siglos. En efecto, tras una guerra por el dominio de las tierras alavesas, Alfonso VIII de Castilla y Sancho el Sabio de Navarra firman la transacción de 1179, por la que Castilla cede a Navarra el territorio alavés, excepto Castellar y Treviño. Más tarde, Castilla fue invadida por León y Navarra, pero Alfonso VIII recuperó los territorios perdidos. Después del año 1200, en que Alfonso VIII conquista Alava e Ibida, completando el dominio de este último territorio con Treviño y Portilla mediante cambio, no se halla en las fuentes mención expresa de dependencia de Ibida respecto a Alava.

En 1332, la Cofradía de Alava decide someterse al señorío del Rey de Castilla, Alfonso XI; en este momento, el Condado de Treviño no formaba parte de dicha Cofradía. Ni siquiera hay noticia documental de que perteneciese en algún momento a la misma.

En 1366, Enrique II le da a su Adelantado mayor en Castilla, Don Pedro Manrique, la villa de Treviño con sus aldeas, instituyendo mayorazgo de varón. Hacia 1453 fue hecho Conde de Treviño don Diego Gómez Manrique. En 1482, los Reyes Católicos facultan a Don Pedro Manrique, Conde de Treviño, para incorporar Nájera a su antiguo mayorazgo, obteniendo, finalmente, el título de Duque de Nájera. En 1593, Felipe II concede al Duque de Nájera, a petición de éste, que concurra en la persona de su hijo mayor el título de Conde de Treviño, que afirmaba seguir conservando. 
En opinión de Gómez Fernández (13), el hecho de que los reyes de Castilla den su villa, con sus aldeas y términos, pone de manifiesto que aquellas tierras eran realengo y, por tanto, diferentes y separadas de Alava, que tenía un régimen especial hasta su sumisión al señorío real. Entre las villas realengas de aquella región estaban Vitoria, Treviño y Arganzón. Ello corrobora que el Condado de Treviño no tenia vida común con la Cofradía de Alava. Concluye el citado autor diciendo que la razón última de la adscripción de Treviño a Burgos radica, precisamente, en el hecho de haber sido realengo.

Finalmente, cabe señalar que el señorío concedido por el Rey de Castilla en el siglo XIV seguía vigente a principios del siglo XIX y que en el Diccionario Histórico-Geográfico de 1802 no figura el Condado como parte de Alava. Así las cosas, la división provincial de 1833 dio al mencionado Condado la configuración geográfica que tiene hoy día.

Como puede verse, la adscripción del Condado de Treviño a Castilla-León no carece de fundamento histórico. Sin embargo, está extendida la opinión de que resulta manifiesta la artificialidad y anacronismo que supone mantener esta situación, como lo pone de manifiesto el hecho de que los vecinos del Condado realicen su vida cotidiana en Vitoria. Los inconvenientes que viene originándoles esta anómala situación, básicamente derivados de hallarse a un centenar de kilómetros de Burgos y a una quincena de Vitoria, han dado lugar desde 1919 a tradicionales intentos de incorporación a Alava. Sin embargo, pese a lo anómalo de su situación y a las constantes muestras de voluntad incorporacionista por parte de los vecinos del Condado de Treviño, éste se ha mantenido como un enclave perteneciente a la provincia de Burgos, sin que ocurra lo mismo en el terreno eclesiástico, ya que desde el 15 de febrero de 1951 está incorporado a Alava.

El tema de los enclaves ha sido objeto de atención en los sucesivos Estatutos de Autonomía del País Vasco. El Proyecto de Estatuto de 1931 establecía un procedimiento basado en la simple solicitud de la mayoría de los habitantes del enclave. El artículo 8 del Proyecto de Estatuto de 1933 establecía tres requisitos: solicitud del Ayuntamiento o mayoría de los Ayuntamientos, aprobación del Parlamento Vasco y de las Cortes Generales, previa audiencia de la provincia o región a cuya jurisdicción perteneciera el enclave. El vigente Estatuto de Autonomía del País Vasco (14) ha regulado en su artículo 8, claramente inspirado en el del Proyecto de 1933, un procedimiento de incorporación de enclaves intracomunitarios situados en su territorio. Dicho artículo es del siguiente tenor literal: "Podrán agregarse a la Comunidad Autónoma de País Vasco otros territorios o municipios que estuvieran enclavados en su totalidad dentro del territorio de la misma, mediante el cumplimiento de los requisitos siguientes:

a) Que soliciten la incorporación el Ayuntamiento o la mayoría de los Ayuntamientos interesados, y que se oiga a la Comunidad o provincia a la que pertenezcan los territorios o municipios a agregar.

b) Que lo acuerden los habitantes de dicho municipio o territorio mediante referéndum expresamente convocado, previa la autorización competente al efecto y aprobado por mayoría de los votos válidos emitidos. 
c) Que lo aprueben el Parlamento del País Vasco y, posteriormente, las Cortes Generales del Estado, mediante ley orgánica.

Al amparo de este precepto del Estatuto y casi inmediatamente después de su aprobación, los Ayuntamientos de La Puebla de Arganzón y de Treviño adoptaron, con fechas 17 de octubre y 26 de enero de 1980, respectivamente, sendos acuerdos de incorporación a la provincia de Alava y a la Comunidad Autónoma del País Vasco. Posteriormente, acordaron dar audiencia, de conformidad con lo previsto en el apartado a) del citado artículo a la Comunidad o provincia a la que pertenecen, concediendo un plazo de 15 días al Consejo Regional de Castilla y León y a la Diputación Provincial de Burgos para que formularan las alegaciones que estimaren pertinentes. El 16 y 24 de enero de 1981, las Corporaciones municipales de La Puebla de Arganzón y de Treviño acordaron acumular los respectivos expedientes y elevar al Gobierno la documentación acreditativa del cumplimiento de los requisitos establecidos en el apartado a) del artículo 8 del Estatuto vasco, a fin de que autorizara la convocatoria de un referéndum en el que los habitantes de dichos municipios pudieran decidir democráticamente su incorporación a la provincia de Alava y a la Comunidad Autónoma del País Vasco, conforme determina el apartado b) del citado artículo, por ser de la competencia del Gobierno tal autorización. Con fecha de 10 de febrero de 1981, el Jefe de Secretaría del Presidente del Gobierno de la Nación acusó recibo del escrito y anexos dirigidos a éste y dio traslado de todo ello al Ministro de la Presidencia del Gobierno. Pero la autorización requerida no se tramitó, a pesar de las diversas gestiones llevadas a cabo en este sentido a todos los niveles, incluídas negociaciones del Presidente del Gobierno vasco con el Presidente del Gobierno de la Nación.

Así las cosas, en 1983 se aprobó el Estatuto de Autonomía de Castilla y León (15), cuya Disposición Transitoria 7, en su apartado 3, establece un procedimiento de segregación de enclaves. Dicho precepto es del siguiente tenor literal:

"Para que un territorio o municipio que constituya un enclave perteneciente a una provincia integrada en la Comunidad Autónoma de Castilla y León pueda segregarse de la misma e incorporarse a otra Comunidad Autónoma será necesario el cumplimiento de los siguientes requisitos:

a) Solicitud de segregación formulada por el Ayuntamiento o Ayuntamientos interesados, mediante acuerdo adoptado con el voto favorable de las dos terceras partes del número de hecho y, en todo caso, de la mayoría absoluta de los miembros de dicha o dichas Corporaciones.

b) Informe de la provincia a la que pertenezca el territorio o municipio a segregar y de la Comunidad Autónoma de Castilla y León, favorable a tal segregación, a la vista de las mayores vinculaciones históricas, sociales, culturales, y económicas con la Comunidad Autónoma a la que se solicite la incorporación. A tal efecto, la Comunidad Autónoma de Castilla y León podrá realizar encuestas y otras formas de consulta con objeto de llegar a una más motivada resolución.

c) Refrendo entre los habitantes del territorio o municipio que pretende la segregación, aprobado por mayoría de los votos válidos emitidos. 
d) Aprobación por las Cortes Generales, mediante Ley Orgánica.

En todo caso, el resultado de este proceso quedará pendiente del cumplimiento de los requisitos de agregación exigidos por el Estatuto de la Comunidad Autónoma a la que se pretende la incorporación".

A la vista de este precepto, el Gobierno y el Parlamento vascos presentaron recurso de inconstitucionalidad contra el mismo, habida cuenta de que exigía requisitos no pevistos por el artículo 8 del Estatuto vasco: la mayoría necesaria para adoptar el acuerdo inicial por los Ayuntamientos del enclave en cuestión y el informe favorable de la Comunidad Autónoma a la que pertenece el mismo.

El principal argumento que esgrimian era el de considerar que la mencionada Disposición Transitoria del Estatuto castellano-leonés era inconstitucional por antiestatutaria, al violar la rigidez formal de los Estatutos (en este caso del Estatuto vasco) consagrada en los artículos 147.3 y 152.2 de la Constitu-ción.

Sin embargo, el Tribunal Constitucional desestimó, en su ya mencionada Sentencia 99/86, las pretensiones del Gobierno y el Parlamento vascos, estableciendo que debía aplicarse los procedimientos de ambos Estatutos acumuladamente para el cambio de adscripción de los correspondientes enclaves.

En cuanto a los razonamientos jurídicos de dicha Sentencia, el Tribunal parte de la base de que "...el único parámetro para enjuiciar la validez constitucional de una disposición incluída en un Estatuto de Autonomía es la propia Constitución", no siendo admisible cotejar directamente preceptos estatutarios diversos.

El artículo 147.2. b) de la Constitución establece como contenido mínimo de los Estatutos la delimitación del territorio de la respectiva Comunidad. El Tribunal entiende que cabe incluir también aquí los procedimientos de alteración de dicho territorio y que, además, el hecho de que el artículo 147 establezca como contenido mínimo de los Estatutos ciertas materias es, al mismo tiempo, una garantía de que éstas no serán objeto de regulación fuera del correspondiente Estatuto, "pues ello entrañaría la mediatización de la directa infraordenación de los Estatutos a la Constitución, siendo así que, como hemos señalado anteriormente, ésta constituye el único límite que pesa sobre ellos. La predeterminación del contenido de unos Estatutos por otros en virtud, meramente, de la contingencia de su momento de aprobación, ampliaría los límites en que han de enmarcarse los contenidos estatutarios. ...De todo lo anterior se deduce que, contra lo que los recurrentes entienden, el Estatuto de una Comunidad Autónoma no puede regular de un modo 'completo y acabado' la segregación y correspondiente agregación de los enclaves ubicados en su territorio cuando éstos pertenecen al de otra Comunidad Autónoma. La regulación estatutaria no puede contener el procedimiento de modificación territorial que deberán seguir las dos Comunidades implicadas, sino tan sólo el proceso de formación y manifestación de la voluntad de cada una de ellas para perfeccionar -mediante actos distintos pero complementarios- el complejo procedimiento en que consiste la segregación de un enclave y su agregación a otra Comunidad". Por tanto, llega a la conclusión de que el Estatuto vasco sólo puede regular la agregación de los enclaves situados en territorio del País Vasco, mientras que la regulación de la segrega- 
ción queda reservada al Estatuto de la Comunidad a la que pertenecen dichos enclaves y, en el caso del Condado de Treviño, al Estatuto castellano-leonés.

El razonamiento del Tribunal es compartido, entre otros, por Martín Mateo (16), Ruipérez Alamillo (17) y Rivero Ysern (18).

El Magistrado Jesús Leguina Villa formuló un voto particular a esta Sentencia, discrepando del fallo de la misma. Entiende este Magistrado que el Tribunal debía haber declarado la inaplicabilidad de la disposición impugnada al caso del Condado de Treviño, al impedir los artículos 147.3 y 152.2 de la Constitución cualquier reforma de los Estatutos que no se ajuste al procedimiento establecido en los mismos: "Si a un mismo enclave -en el caso, el Condado de Treviño- se aplicara la Disposición transitoria séptima, 3, del Estatuto de Castilla-León, que regula de modo parcialmente contradictorio el camino a seguir para la integración de dicho enclave en el territorio del País Vasco, se estaría automáticamente inaplicando el citado artículo 8 del Estatuto vasco, lo que es tanto como decir que este precepto estatutario resultaría derogado o modificado, al menos parcialmente, por una vía distinta de la señalada en el artículo 152.2 de la Constitución y en el artículo 46 del propio Estatuto vasco. Como quiera que la Constitución prohibe cualquier modificación extra ordinem de los Estatutos, resulta forzoso concluir que la validez de la norma transitoria del Estatuto castellano-leonés sólo es posible si se entiende que queda fuera de su ámbito de aplicación el supuesto del enclave territorial contemplado y regulado por el artículo 8 del Estatuto vasco. Una conclusión distinta, como es la que se mantiene en la Sentencia mayoritaria, implica admitir la posibilidad de derogación o modificación de un Estatuto anterior por otro posterior, con inobservancia o desconocimiento del mandato constitucional antes dicho".

Este último razonamiento es defendido, entre otros, por Larumbe Biurrun (19) y Sánchez Blanco (20).

Luis María Díez-Picazo (21) considera correcto el fallo del Tribunal, aunque matiza algunos puntos de la argumentación recogida en la Sentencia. A diferencia de ésta, entiende que es perfectamente posible que un Estatuto -en este caso el vasco-regule de forma completa y acabada el procedimiento de incorporación de enclaves situados en su territorio. En cuanto a la eventual objeción de que tan sólo el Estatuto de Autonomía de Castilla y León estaba constitucionalmente habilitado para regular la segregación-agregación del Condado de Treviño y que la regulación efectuada por el Estatuto vasco significa una extralimitación y sería inaplicable porque el principio de territorialidad de las normas de Derecho Público le impediría desplegar su eficacia en territorio no vasco, Díez-Picazo replica anticipadamente con un argumento a todas luces acertado: "los Estatutos de Autonomía son leyes orgánicas dictadas por el Estado y, por ello, vinculan indiscriminadamente en todo el territorio nacional, según su fórmula de promulgación se ocupa de advertir".

El argumento básico en que se basa para no considerar correcto el razonamiento del Magistrado Leguina Villa es el de entender que las cláusulas de rigidez estatutaria no son aplicables entre los propios Estatutos de Autonomía. Entiende que "... la afirmación de la operatividad de las cláusulas de rigidez estatutaria frente a otros Estatutos lleva inevitablemente a sostener la jerarquización entre Estatutos de 
Autonomía. Y ello repugna también a la conciencia del jurista porque no tiene apoyo constitucional alguno, porque todos poseen la misma naturaleza, porque todos forman parte del bloque de la constitucionalidad y, sobre todo, por una razón aún más profunda, a saber: esa jerarquización estaría determinada por el mero hecho de que unos Estatutos se promulgaron antes que otros,... esta postura significa que también en materia de autonomía la antigüedad es un grado".

Curiosamente, el propio Diez-Picazo nos da la clave para descubrir la incorrección de su razonamiento al afirmar: "... hoy día es pacífico en la doctrina española, con el decisivo respaldo de la jurisprudencia constitucional, que no todo caso de rigidez -esto es, de especiales requisitos que dificultan la modificación o derogación de una norma, dotándola de una peculiar fuerza pasiva- es expresión de una diferencia de rango jerárquico. Valga por todos el ejemplo de las leyes orgánicas...". Y, en efecto, esto es lo que sucede en el caso del razonamiento del voto particular. Afirmar, como hacemos los que compartimos dicho razonamiento, que las cláusulas de rigidez estatutaria sí son aplicables entre los propios Estatutos no supone necesariamente partir de la premisa de que entre ellos hay diferencias jerárquicas. Cosa distinta es que una interpretación literal del artículo 147.3 de la Constitución conlleve el mismo resultado práctico que si se partiera de dicha premisa, al producirse el efecto que Díez-Picazo describe gráficamente al decir que "también en materia de autonomía la antigüedad es un grado". Pero el hecho de que este efecto no sea considerado conveniente desde un punto de vista de política legislativa no permite afirmar que las cláusulas de rigidez estatutaria no son aplicables entre Estatutos, porque ello supone sencillamente obviar la literalidad del artículo 147.3 de la Constitución, cuya interpretación no deja lugar a dudas. Por otra parte, habida cuenta de la naturaleza de los Estatutos, son muy escasos, en la práctica, los supuestos en los que pueden entrar en colisión entre sí.

En definitiva, la Constitución establece que los Estatutos de Autonomía son leyes orgánicas y, por tanto, tal es el rango que tienen. La rigidez estatutaria obedece al carácter paccionado de los Estatutos (22) pero ello no implica, desde el punto de vista formal, un mayor rango jerárquico (23).

En cuanto al argumento del Tribunal Constitucional según el cual los procedimientos de alteración del territorio de una Comunidad Autónoma forman parte del contenido mínimo de su Estatuto, no parece que sea acorde con la literalidad del artículo 147.2.b) de la Constitución, que sólo habla de delimitación del territorio. Prueba de ello es que, como hemos visto en el epígrafe anterior, muy pocos Estatutos han regulado de modo específico esta cuestión.

Para terminar, resulta oportuno recordar que, hasta el momento de aprobarse el Estatuto vasco, el Estado tenía plena disponibilidad en lo que se refiere a los enclaves intracomunitarios situados en la Comunidad Autónoma del País Vasco. Podría no haber admitido regulación alguna de esta materia en el Estatuto; por contra, también podría haber utilizado la Ley Orgánica que aprobó dicho Estatuto para adscribir directamente el Condado de Treviño a Alava. Y, en uso de esa plena disponibilidad, pactó con los representantes de los territorios vascos que accedían a su autonomía un procedimiento de incorporación que, dado ese carácter paccionado, queda 
protegido, al igual que el resto del Estatuto, por la rigidez formal consagrada en los artículos 147.3 y 152.2 de la Constitución. Cuando los castellano-leoneses accedieron a la autonomía ya no podían reivindicar su derecho a regular la segregación del Condado de Treviño, porque esa regulación ya había sido hecha tres años antes por quien tenia plena disponibilidad para hacerlo, quedando afectada por la rigidez estatutaria.

Lo cierto es que la Sentencia comentada volvió a dejar en vía muerta la cuestión del Condado de Treviño, dando al traste con un nuevo intento de incorporación a Alava.

Como conclusión final bien puede decirse, dado el escaso interés que, en general, despierta la cuestión de los enclaves, que el fin de éstos no se adivina ni siquiera a largo plazo.

NOTAS.

(1) Sentencia del Tribunal Constitucional 99/86 de 11 de julio. B.O.E. de 23 de julio de 1986.

(2) GOMEZ FERNANDEZ, L., "Apostillas históricas a la Sentencia del Tribunal Constitucional sobre la incorporación de Treviño al País Vasco", en Revista de Derecho Público, núms. 104-105, pág. 611.

(3) MARTIN-RETORNILLO, S., "En torno a la organización provincial", en Revista de Administración Pública, num. 93, págs. 17 y ss.

(4) Acerca del reconocimiento que el vigente Reglamento de Población y Demarcación (Real Decreto 1690/1986) hace de los enclaves municipales existentes, véase su art. 1.

(5) LARUMBE BIURRUN, P.M., El territorio de la Comunidad Autónoma: notas jurídicas, IVAP, Oñati, 1988, pág. 62.

(6) Sin embargo, no es infrecuente encontrar textos en los que se afirma que el Rincón de Ademuz es un enclave de la Comunidad Valenciana dentro de Aragón. La consulta de cualquier mapa demuestra lo incorrecto de tal afirmación.

(7) MATEU I LLOPIS, El País Valencià, Valencia,1933, pág 101.

(8) Real Decreto Legislativo 781/1986, de 18 de abril. B.O.E. núm. 96, de 22 de abril.

(9) Ley Orgánica 2/80, de 18 de enero. B.O.E. núm. 20, de 23 de enero de 1980.

(10) RIVERO YSERN Y OTROS, Comentarios al Estatuto de Autonomía de la Comunidad Autónoma de Castilla y León, IDEAL, Madrid, 1985, págs. 335 y 336.

(11) DIEZ-PICAZO, L.M., "Sobre la delimitación estatutaria del territorio de las Comunidades Autónomas y la rigidez estatutaria", en Revista Española de Derecho Constitucional, núm. 20, 1987, pág. 149.

(12) El artículo 10 del Estatuto de Autonomía de Aragón es del siguiente tenor literal:

"Podrán incorporarse a la Comunidad Autónoma de Aragón otros territorios o municipios, limítrofes o enclavados, mediante el cumplimiento de los requisitos siguientes, sin perjuicio de otros que puedan legítimamente exigirse:

a) Que soliciten la incorporación el Ayuntamiento o la mayoría de los Ayuntamientos interesados y que se oiga a la Comunidad o provincia a la que pertenezcan los territorios o municipios a agregar. 
b) Que lo acuerden los habitantes de dichos municipios o territorios, mediante consulta expresamente convocada al efecto y previa la autorización competente.

c) Que lo aprueben las Cortes de Aragón y, posteriormente, las Cortes Generales del Estado, mediante Ley Orgánica".

(13) GOMEZ FERNANDEZ, L., "Apostillas históricas...", cit., págs. 620 y 621.

(14) Ley Orgánica 3/79 de 18 de diciembre. B.O.E. de 22 de diciembre de 1979.

(15) Ley orgánica 4/83 de 25 de febrero. B.O.E. de 2 de marzo de 1983.

(16) MARTIN MATEO, R., Manual de Derecho Autonómico, Madrid, 1986, pág. 95.

(17) RUIPEREZ ALAMILlO, J., "Problemas en la determinación territorial de las Comunidades Autónomas", R.E.P., núm. 56, pág. 178.

(18) RIVERO YSERN Y OTROS, "Comentarios...", cit., págs. 335 y 336.

(19) LARUMBE BIURRUN, P.M., El territorio..., cit., pág. 80.

(20) SANCHEZ BLANCO, A., "Ajustes territoriales en las Comunidades Autónomas. Derechos institucionales y derecho de las comunidades sociales. La Sentencia del Tribunal Constitucional 99/1986 relativa al Condado de Treviño", en R.V.A.P., núm. 16, 1986, págs. 153 y 154.

(21) DIEZ-PICAZO, L.M., "Sobre la delimitación...", cit., págs. 166 y 167.

(22) Dicho carácter paccionado, ampliamente admitido en la doctrina, es rechazado a su vez por DIEZ-PICAZO, L.M., en "Sobre la delimitación...", cit., pág. 165.

(23) Puede verse en este sentido la explicación dada por TORRES DEL MORAL, A., Principios de Derecho Constitucional, Madrid, 1985, tomo 1, págs. 54 y 55. 